\title{
Evaluating the Effects of Repeated Psychological Injury: an Introduction to the Special Issue
}

\author{
Tyson D Bailey ${ }^{1} \cdot$ Lisa Rocchio ${ }^{2}$ \\ Published online: 20 June 2020 \\ (C) Springer Science+Business Media, LLC, part of Springer Nature 2020
}

Trauma-informed forensic psychology is an intersection of two specialized practice areas, both requiring advanced knowledge and a continually evolving understanding of psychological and legal constructs (Dalenberg, Straus, \& Ardill, 2017; Frankel, 2009; Frankel \& Dalenberg, 2006). In essence, functioning effectively in the psycholegal world requires one to maintain a bicultural stance that navigates systems that are not always compatible. Given the high prevalence of traumatic events (see articles in this section for review), forensic practitioners are quite likely to be asked to evaluate individuals who have experienced trauma and its effects, whether or not it is known to the person requesting the evaluation. Further, experiencing trauma increases the risk of myriad problematic outcomes, including involvement in the legal system (Dalenberg et al., 2017). Unfortunately, encounters with the legal system do not follow a trauma-informed process, nor are they meant to be therapeutic. Even when one experiences a hoped-for outcome, such as a reduction in sentence, drop in charges, or a monetary award, the legal process frequently exacerbates symptoms. In a forensic context, where a motivation might exist to misrepresent levels of psychological distress, the issue of malingering or feigning symptoms must be carefully considered and assessed. Therefore, the assessment of response style necessitates a careful and thorough approach to each evaluation (Brown, 2009; Dalenberg et al., 2017), particularly when complex posttraumatic presentations are present.

Ford and Courtois (2020) define traumatic stressors as those "events, experiences, and exposure - that greatly exceed the individual's capacity to control, cope with, or withstand and that compromise the individual's psychophysiological

Tyson D Bailey

Tyson@DrTysonBailey.com

1 Private Practice, 19221 36th Ave W, Ste 208, Lynnwood, WA 98036, USA

2 Private Practice, 1524 Atwood Avenue, Suite 222, Johnston, RI 02919, USA equilibrium or stasis" (p. 4). Although one event can be sufficient to create lasting distress, the effects are exponentially magnified when the trauma is repeated (particularly in childhood), involves a betrayal of a trusted relationship, and/or a persistent sense of anticipation about the impending abuse (Ford \& Courtois, 2020; Terr, 1991). In addition, those individuals who have experienced complex trauma are also at increased likelihood of interactions with the legal system. Given these considerations, forensic evaluators are encouraged to understand the literature for individuals with complex trauma on their likely biopsychosocial outcomes, diagnoses, and performance on various assessment measures commonly used in practice. It is also critical to understand that effective forensic evaluations rely on multi-measure and multi-source corroboration and include measures that are specifically normed on trauma exposed populations.

Given the complexity of cumulative trauma exposure (Briere, Dietrich, \& Semple, 2016; Briere, Kaltman, \& Greene, 2008), survivors of repeated interpersonal trauma may appear to be feigning or exaggerating symptoms on common psychological measures, even when they are not (Brown, 2009). For example, research has demonstrated how a history of complex trauma and dissociation can result in elevations of the validity scales of common personality measures, as well as stand-alone symptom validity measures (see Brand, Schielke, \& Brams, 2017; Brand, Schielke, Brams, \& DiComo, 2017b for a review in forensic evalutions). Unfortunately, training programs do not regularly provide information on complex posttraumatic reactions and many textbooks inaccurately describe dissociation and the effects of repeated trauma (Brand, 2016; Kissee, Isaacson, \& Miller-Perrin, 2014; Simiola, Smothers, Thompson, \& Cook, 2018; Wilgus, Packer, LileKing, Miller-Perrin, \& Brand, 2015).

\section{Brief Case Example}

Shortly after becoming licensed, the first author conducted a forensic evaluation in which a person had been diagnosed 
with a personality disorder not otherwise specified by a previous forensic evaluator. The results of this decision led the prosecutor to seek the maximum penalty for alleged offense. When reviewing the other psychologist's report and data, which utilized two common personality measures, a semistructured interview, and limited record review, it became apparent that the examiner did not ask about trauma history at any point during the interview. Upon reexamination, the first author learned that the individual had been repeatedly traumatized, and that the trauma included experiences of sexual and emotional abuse as a child with multiple familial perpetrators. Utilizing trauma-informed measures and procedures, the data supported the diagnoses of chronic PTSD (complex PTSD was not yet in the diagnostic nosology) and dissociative disorder NOS, rather than a personality disorder.

Further, while discussing his experiences during the previous evaluation, the evaluee described becoming triggered during the interview and reported that there were no efforts made to help him to manage or reduce his distress. His description of the experience had the markers of depersonalization and derealization, which was consistent with the results of the assessment measures. In addition, the previous report contained no statements suggesting that the previous psychologist recognized the behavioral indicators of potential intrusive or dissociative symptoms or the potential relevance of a trauma history to the individual's psychological functioning and mental status. The report instead strongly asserted that these behavioral indicators supported the personality disorder diagnosis despite only having a single, moderate relevant elevation in the assessment data. When his test results were compared to research that has been conducted with severely traumatized samples, the evaluee's scores and responses, including those on a stand-alone measure of symptom feigning, resulted in valid profiles. Unfortunately, cases like these are common in both authors' experiences, and it is our hope that the scholarly works in this special section increase the understanding of complex posttraumatic reactions in forensic populations.

\section{The Current Issue}

This special section is intended to provide an overview of key ethical, practical, and assessment issues that are imperative to consider when contemplating forensic practice with this complex trauma population. Our goal is to provide evidence-based information that will be useful both for the forensic practitioner wanting additional training in the area of complex trauma and dissociation and for the trauma practitioner seeking continuing education in the area of forensic practice. The information also should be widely disseminated in the legal system, for example, to prosecuting attorneys and to judges who might have to deal with cases of complex PTSD and dissociation. Given the ubiquity of trauma, particularly within the legal system, it is important for forensic evaluators to have a firm understanding of the science, application, and debate within the field.

A central point in the special issue relates to the trauma victim's assessment process. It is critical to note that forensic evaluations need multi-source and multi-measure corroboration; much like an effective study, a single point of data is of limited utility. Comprehensive forensic evaluations therefore require review of external data sources, collateral interviews, psychological testing utilizing measures that assess for response style and malingering, and a clinical interview. For example, behaviors reported or observed during the evaluation that may be associated with a traumatic or dissociative response will need to be considered in light of all of the data. Without additional supporting information, a single observation or report is not considered sufficient information upon which to draw a conclusion within a forensic setting.

Within the seven articles contained in this section, the authors explore a variety of issues relevant to performing trauma-informed forensic psychological evaluations. Bailey and Brown (2020) provide an overview of key diagnostic challenges associated with complex trauma, complex posttraumatic stress disorder, and dissociation within a forensic setting. They provide valuable information that is critical for the forensic evaluator to take into account when assessing an individual who has experienced trauma. Rocchio (2020) reviews ethical and professional considerations and potential pitfalls for forensic psychologists. She addresses psychologists working in various forensic roles such as conducting forensic evaluations, providing scientific framework testimony, or consulting with attorneys. She also highlights the specific applications to trauma-informed forensic evaluations. Brown (2020) addresses the complexity of evaluating a sexual harassment plaintiff who has a history of complex trauma exposure. She discusses the concept of reasonableness in terms of the sexual harassment claim and highlights important considerations for therapists who have a client involved in a lawsuit claiming emotional injury. Dalenberg, Brand, Loewenstein, Frewen, and Spiegel (2020) provide a final response to a series of articles in the present journal discussing the forensic applications of complex trauma literature. In their response, they highlight critical areas of agreement as well as recommendations for future scientific work on the issue.

Abu-Rus, Thompson, Naish, and Dalenberg (2020) provide preliminary information on the development of a validity scale for the Dissociative Experiences Scale, a screening measure commonly used to assess dissociative symptoms. Ellickson-Larew, Escarfulleri, and Wolf (2020) provide an overview of the dissociative subtype of posttraumatic stress disorder, including evaluation strategies and recommendations for future editions of the diagnostic and statistical 
manual of mental disorders (DSMs). Finally, Loewenstein's (2020) article provides a comprehensive case study of an evaluee in a criminal case who experienced severe dissociation and also malingered some aspects of her presentation. This article provides a clear example of the extensive process a trauma-informed forensic evaluator utilized to determine whether a client who met criteria for dissociative identity disorder was competent to stand trial and could bear legal responsibility for her actions.

\section{Future Directions and Conclusions}

Although significant gains have been made in understanding complex posttraumatic reactions, more research and scientific discourse is needed. It is imperative that individuals who have experienced complex trauma are included in research studies to assist forensic evaluators in understanding assessment measure responses, possible treatment recommendations, and effective strategies for gathering information in a traumainformed manner. While maintaining objectivity has been held as the standard within forensic psychology, it is critical to understand that it is not possible to be completely free of bias (Gowensmith \& McCallum, 2019; Sue, 2010). Interestingly, research has shown that forensic evaluators often conceptualize themselves as immune to the effects of bias but readily identify their colleagues as having significant problems (Neal \& Brodsky, 2016). This is not to say there is not a distinct role that evaluators inhabit in a forensic setting; however, despite the systemic pressures on the forensic evaluator, it is possible to clearly communicate one's role, provide an opinion that is consistent with the data (even if it is not favorable to the referring party, to the evaluee, as the case may be), and maintain an empathic stance (Mulay, Mivshek, Kaufman, \& Waugh, 2018).

With the inclusion of complex PTSD in the International Classification of Diseases-11 (ICD-11; World Health Organization, 2018), it is anticipated that research exploring the unique phenomenology, assessment results, and treatment of repeated, inescapable trauma will increase in the coming years. We encourage researchers to design studies that do not exclude chronically traumatized samples and look beyond how many categories of trauma have been experienced. Although a single traumatic incident can be enough to produce lasting distress, the likelihood of disturbances in identity, relationships, emotion regulation, and persistent distress increase exponentially when the instances of trauma cannot be counted because they happened with such frequency and contained moments of agonizing anticipation in between them (Ford \& Courtois, 2020; Terr, 1991).

Judith Herman (1992) described the field of trauma psychology as having "a curious history — one of episodic amnesia" (p. 7) that is frequently brought on by society's reactions to the commonplace nature of unspeakable acts perpetrated on others. Although the number of professional organizations directly dedicated to the study of trauma and its sequelae creates significantly more difficulty with collective amnesia, there continues to be debates about the extent and effects of trauma, particularly in cases that involve complex posttraumatic or dissociative symptoms. It is our hope that special sections like these increase the scientific discourse, particularly within trauma-informed forensic psychology. It is also critical to note that if a person has trauma (single incident or complex) and posttraumatic reactions, they can also be held criminally responsible, engage in feigning, be deceptive in their responses, or affect any of the other important issues evaluators will encounter in the forensic realm. In the end, forensic evaluators must focus on providing an opinion that is consistent with the data, to a reasonable degree of psychological certainty, and the triers of fact will determine what evidence is the most informative for their decision-making process. Psychologists have a crucial role in this regard in providing probative rather than prejudicial information to the court, and especially for cases that are hard to disentangle psychologically and legally, such as in cases of complex trauma, dissociation, and PTSD, as presented in depth in the present special issue.

\section{References}

Abu-Rus, A., Thompson, K. J., Naish, B., \& Dalenberg, C. J., (2020) Development of a validity ccale for the dissociative experience scale-revised: Atypicality, structure, and inconsistency. Psychological Injury and Law.

Bailey, T. D. \& Brown, L. S. (2020). Complex trauma: Missed and misdiagnosis in forensic evaluations. Psychological Injury and Law.

Brand, B. L. (2016). The necessity of clinical training in trauma and dissociation. Journal of Anxiety and Depression, 5(4). https://doi. org/10.4172/2167-1044.1000251.

Brand, B. L., Schielke, H. J., \& Brams, J. S. (2017). Assisting the courts in understanding and connecting with experiences of disconnection: Addressing trauma-related dissociation as a forensic psychologist, part I. Psychological Injury and Law, 10(4), 283-297. https://doi. org/10.1007/s12207-017-9304-8.

Brand, B. L., Schielke, H. J., Brams, J. S., \& DiComo, R. A. (2017). Assessing trauma-related dissociation in forensic contexts: Addressing trauma-related dissociation as a forensic psychologist, part II. Psychological Injury and Law, 10(4), 298-312. https://doi. org/10.1007/s12207-017-9305-7.

Briere, J., Dietrich, A., \& Semple, R. J. (2016). Dissociative complexity: Antecedents and clinical correlates of a new construct. Psychological Trauma Theory Research Practice and Policy, 8(5), 577-584.

Briere, J., Kaltman, S., \& Greene, R. (2008). Accumulated childhood trauma and symptom complexity. Journal of Traumatic Stress, 21(2), 223-226. https://doi.org/10.1002/jts.

Brown, L. S. (2009). True drama or true trauma? Forensic trauma assessment and the challenge of detecting malingering. In P. F. Dell \& J. 
A. O'Neil (Eds.), Dissociation and the dissociative disorders: DSM$V$ and beyond (pp. 585-594). New York: Routledge.

Brown, L. S. (2020). Complex trauma and the question of reasonableness of response in sexual harassment cases: Issues for treatment providers and forensic evaluators. Psychological Injury and Law.

Dalenberg, C. J., Brand, B. L., Loewenstein, R. J., Frewen, P. A., \& Spiegel, D. (2020). Inviting scientific discourse on traumatic dissociation: Progress made and obstacles to further resolution. Psychological Injury and Law.

Dalenberg, C. J., Straus, E., \& Ardill, M. (2017). Forensic psychology in the context of trauma. In S. N. Gold (Ed.), APA handbook of trauma psychology: Trauma practice (pp. 543-563). Washington, DC: American Psychological Association.

Ellickson-Larew, S., Escarfulleri, S., \& Wolf, E. J. (2020). The dissociative subtype of PTSD: Forensic considerations and recent controversies. Psychological Injury and Law.

Ford, J. D., \& Courtois, C. A. (2020). Defining and understanding complex trauma and complex traumatic stress disorders. In C. A. Courtois \& J. D. Ford (Eds.), Treating complex traumatic stress disorders in adults: Scientific foundations and therapeutic models (2nd ed., pp. 3-34). New York: Guilford Press.

Frankel, A. S. (2009). Clinical and forensic assessment with adults. In P. F. Dell \& J. A. O'Neil (Eds.), Dissociation and the dissociative disorders: DSM-V and beyond. New York: Taylor \& Francis Group.

Frankel, A. S., \& Dalenberg, C. J. (2006). The forensic evaluation of dissociation and persons diagnosed with dissociative identity disorder: Searching for convergence. Psychiatric Clinics of North America, 29(1), 169-184. https://doi.org/10.1016/j.psc.2005.10. 002.

Gowensmith, W. N., \& McCallum, K. E. (2019). Mirror, mirror on the wall, who's the least biased of them all? Dangers and potential solutions regarding bias in forensic psychological evaluations. South Africa Journal of Psychology, 49(2), 165-176. https://doi. org/10.1177/0081246319835117.

Herman, J. L. (1992). Trauma and recovery. New York: Basic Books.

Kissee, J. L., Isaacson, L. J., \& Miller-Perrin, C. (2014). An analysis of child maltreatment content in introductory psychology textbooks.
Journal of Aggression, Maltreatment \& Trauma, 23(3), 215-228. https://doi.org/10.1080/10926771.2014.878891.

Loewenstein, R. J. (2020). Firebug! Dissociative identity disorder? Malingering? Or...? An intensive case study of an arsonist. Psychological Injury and Law.

Mulay, A. L., Mivshek, M., Kaufman, H., \& Waugh, M. H. (2018). The ethics of empathy: Walking a fine line in forensic evaluations. Journal of Forensic Psychology Research and Practice, 18(4), 320-336. https://doi.org/10.1080/24732850.2018.1490682.

Neal, T., \& Brodsky, S. L. (2016). Forensic psychologists' perceptions of bias and potential correction strategies in forensic mental health evaluations. Psychology, Public Policy, and Law, 22(1), 58.

Rocchio, L. (2020). Ethical and professional considerations in forensic assessment of complex trauma and dissociation. Psychological Injury and Law.

Simiola, V., Smothers, B., Thompson, R., \& Cook, J. M. (2018). A national survey of trauma training in psychology internships. Journal of Aggression, Maltreatment \& Trauma, 27(3), 309-322. https://doi.org/10.1080/10926771.2017.1311977.

Sue, D. W. (2010). Microaggressions in everyday life: Race, gender, and sexual orientation. Hoboken, NJ: John Wiley \& Sons, Inc..

Terr, L. (1991). Childhood traumas: An outline and overview. American Journal of Psychiatry, 148, 10-20.

Wilgus, S. J., Packer, M. M., Lile-King, R., Miller-Perrin, C. L., \& Brand, B. L. (2015). Coverage of child maltreatment in abnormal psychology textbooks: Reviewing the adequacy of the content. Psychological Trauma: Theory, Research, Practice, and Policy. doi:https://doi.org/10.1037/tra0000049, https://doi.org/10.1037/ tra0000049.supp (Supplemental)

World Health Organization. (2018). International statistical classification of diseases and related health problems (11th Revision). Retrieved from $\mathrm{https}$ ://icd.who.int/browse11/1-m/en

Publisher's Note Springer Nature remains neutral with regard to jurisdictional claims in published maps and institutional affiliations. 